\title{
EVALUATION OF RESOURCES CARRYING CAPACITY IN CHINA BASED ON REMOTE SENSING AND GIS
}

\author{
K. Liu ${ }^{1}$, Y.H. Gan ${ }^{1}$, T. Zhang ${ }^{1}$, Z. Y. Luo ${ }^{1}$, J. J. Wang ${ }^{1}$, F. N. Lin ${ }^{2}$ \\ ${ }^{1}$ Satellite, Surveying and Mapping Application Center, NASG, Beijing 100048, China - (liuk, ganyuhang, zhangt, luozy, \\ wangjj)@sasmac.cn \\ ${ }^{2}$ Ningbo Shiyou Information Technology Co., Ltd.- 181191804@qq.com
}

\section{ICWG III/IVc}

KEY WORDS: carrying capacity, CCRR, model modification, remote sensing

\begin{abstract}
:
This paper accurately extracted the information of arable land, grassland (wetland), forest land, water area and construction land, based on 1: 250000 basic geographic information data. It made model modification of comprehensive CCRR to achieve carrying capacity calculation taking resource quality into consideration. Ultimately it achieved a comprehensive assessment of CCRR status in China. The top ten cities where the status of carrying capacity of resources was overloaded were Wenzhou, Shanghai, Chengdu, Baoding, Shantou, Jieyang, Dongguan, Fuyang, Zhoukou and Handan. The cities were basically distributed in the central and southern areas with convenient transportation and more economically developed areas. Among the cities in surplus status, resources carrying capacity in Hulun Buir was the most abundant, followed by Heihe, Bayingolin Mongol Autonomous Prefecture, Qiqihar, Chifeng and Jiamusi, all of which were located in northeastern China with a small population and plentiful cultivated land.
\end{abstract}

\section{INTRODUCTION}

Due to the rapid population expansion in recent decades, the contradictions between human and resources have become increasingly prominent. What is the reasonable population capacity? This involves the concept of carrying capacity. Carrying capacity is the maximum load the object can withstand without any damage. The thought of carrying capacity can be traced back to the research on relations between land productivity and economic wealth in economic accounting table by French economist Francois Quesnay in 1758 and the research on the role of natural factors in limiting population growth in population principle by French T. Malthus in 1798 (Tao, 2003).

The resources carrying capacity is the quantity and quality of resources in a country or a region, which is crucial to sustainable development and development scale of a country or region. The social and economic development is limited to the carrying capacity of resources. Various concepts of carrying capacity of resources and corresponding carrying capacity theories were introduced on different development stages and resources conditions. But these concepts or theories were mainly concentrated on the carrying capacities of natural resources, among which, the carrying capacities of land and water resources have been studied for a long time and obtained fruitful research results were obtained (Allan, 1949; Niu, 1994; Di et al., 2007). The Chinese scholars have made extensive researches on the carrying capacity on the basis of absorbing foreign experiences. At the end of the1940s, Ren Mei'e, the first scholar concerning the research on carrying capacity in China, calculated the carrying capacity of the land agricultural productivity by researching on geographical distribution of crops productivity in Sichuan Province. Since the end of the $20^{\text {th }}$ century, the concept of the carrying capacity and its calculation method have been constantly improved, and a set of models of appraising the ideal situation of regional carrying capacities in different periods with international standards have been formed, among which, ecological carrying capacity model and ecological footprint model are the most representative models (Wackernagel and Rees, 1996; Wackernael et al., 1997). These models now are widely being used in the field of regional sustainability evaluation in China.

Carrying capacity of relative resource (CCRR) was introduced firstly by Huang and Kuang (2000) and refers to "taking the specific one or more regions (reference zones) as a benchmark, calculating relative carrying capacity of resources in the research area, according to the possession of resources or consumption per capita in the reference zone and resources stock of the research area". As an assessment method of regional sustainability, CCRR has been widely accepted (Zhang, 2004).

Since the concept of CCRR was proposed in 2000, many scholars have made improvements to adapt to the social development. However, most of them focused on the selection of resource indicators and the change of calculation methods, which were still limited to the amount of resources and neglected the quality of resources. Moreover, most of the research objects were some provinces and cities, and there was a lack of spatial, quantified, and precise research at country scale. Our research work involved: (1) accurately extracted the information of arable land, grassland (wetland), forest land, water area and construction land, based on 1: 250000 basic geographic information data. (2) made model modification of comprehensive CCRR to achieve carrying capacity calculation taking resource quality into consideration. (3) achieved a comprehensive assessment of CCRR status in China. 


\section{DATA AND METHOD}

\subsection{Data source}

1:250000 DLG data (2012), MODIS 250m (2012), SRTM 90m, social and economic statistical data (2012) and other thematic data.

\subsection{Evaluation model of CCRR}

The research objects of CCRR are natural resources and economic resources. Productive land resources (arable land, forest, grassland (wetland), construction land and water area) in the ecological footprint represent natural resources, and GDP stands for the economic resource. Carrying capacity of relative natural resources, carrying capacity of relative economic resources and comprehensive CCRR can be calculated with livable cities as the reference area.

Carrying capacity of relative natural resources:

$$
\mathrm{C}_{\mathrm{rl}}=\mathrm{I}_{1} * \mathrm{Q}_{1}
$$

Where $\mathrm{C}_{\mathrm{rl}}$ is carrying capacity of relative natural resources, $\mathrm{Q}_{\mathrm{l}}$ is the area of productive land resource, $\mathrm{I}_{1}=\mathrm{Q}_{\mathrm{p} 0} / \mathrm{Q}_{10}$ is the index of natural resources carrying capacity, $\mathrm{Q}_{\mathrm{p} 0}$ is the population in reference area, $\mathrm{Q}_{10}$ is the area of productive land resources in reference area.

Carrying capacity of relative economic resources:

$$
\mathrm{C}_{\mathrm{re}}=\mathrm{I}_{\mathrm{e}}^{*} \mathrm{Q}_{\mathrm{e}}
$$

Where $\mathrm{C}_{\mathrm{re}}$ is carrying capacity of relative economic resources, $\mathrm{Q}_{\mathrm{e}}$ is the area of productive land resource, $\mathrm{I}_{\mathrm{e}}=\mathrm{Q}_{\mathrm{p} 0} / \mathrm{Q}_{\mathrm{e} 0}$ is the index of economic resources carrying capacity, $\mathrm{Q}_{\mathrm{e} 0}$ is the gross economic value in reference area, $\mathrm{Q}_{\mathrm{p} 0}$ is the same as above.

\section{Comprehensive CCRR:}

The comprehensive CCRR is obtained by linear weighted calculation of carrying capacity of relative natural resources and carrying capacity of relative economic resource:

$$
\mathrm{C}_{\mathrm{s}}=\mathrm{w}_{1} \mathrm{C}_{\mathrm{rl}}+\mathrm{w}_{2} \mathrm{C}_{\mathrm{re}}
$$

$\mathrm{w}_{1}$ and $\mathrm{w}_{2}$ are weight coefficients.

Carrying status:

By comparing the calculated theoretical number of comprehensive CCRR with the actual population scale, we can get the carrying state of the research area relative to the reference area.

\subsection{Model modification}

Cultivated land is the most important productive land type, whose quality disequilibrium is dominant in China. So we proposed an improved model of CCRR. Cultivated land quality assessment indicators were abstracted from MODIS multispectral image, e.g. NDVI, DVI and RVI, which represented soil fertility, water availability and soil degradation respectively. The assessment indicator system was constructed using the indicators mentioned above. By virtue of PSR framework, the assessment model was developed in order to explore the feasibility of RS technology in cultivated land quality assessment.

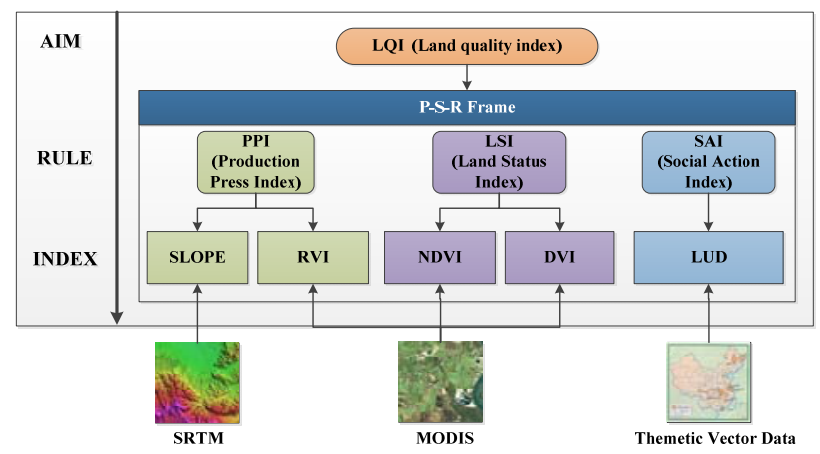

Figure 1. An improved model of CCRR

\subsection{Technical route}

Based on 1: 250000 basic geographic information data, precise arable land, grassland (wetland), forest land, water area and construction land were extracted. Establish an improved CCRR evaluation model, taking into account the quality of resources. Take the city as the evaluation unit, to realize the nationwide comprehensive CCRR (Fig. 2).

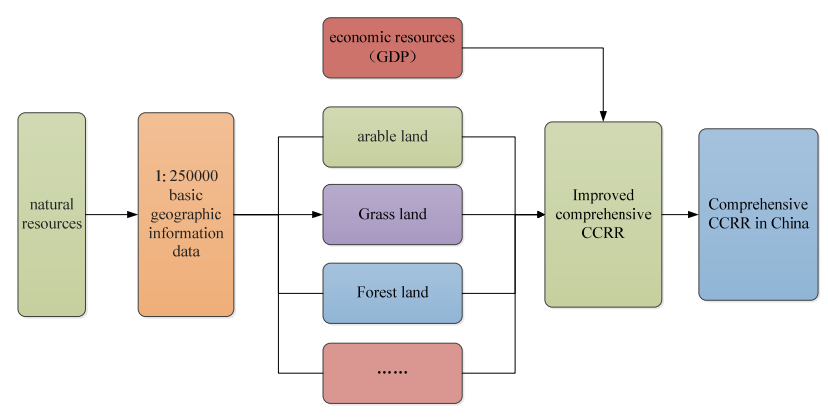

Figure 2. An improved model of CCRR

\section{RESULTS}

\subsection{Carrying capacity of relative natural resources}

According to the data of carrying capacity of relative natural resources, in general, the northern part was higher than the southern part and the carrying capacity of relative natural resources in the southeast and southwestern part was lower than that of other regions. Hulun Buir had the highest natural resource carrying capacity, reaching 41.444 million persons, followed by Chongqing, Qiqihar, Harbin, Heihe (Fig. 3). 


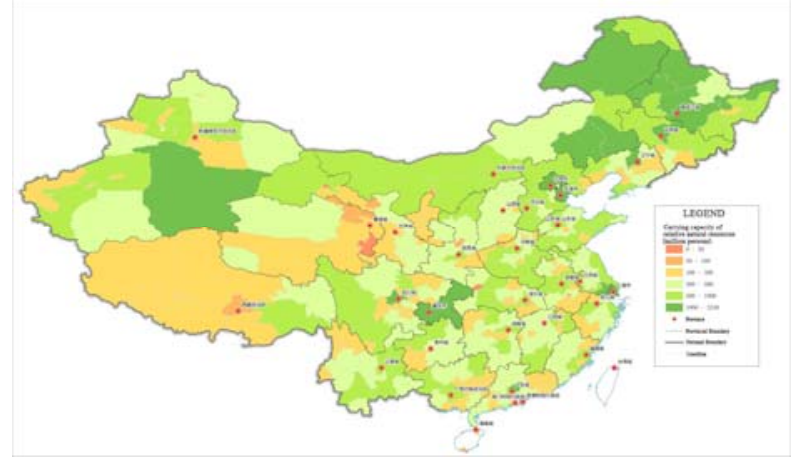

Figure 3. Carrying capacity of relative natural resources in China

\subsection{Carrying capacity of relative economic resources}

From the data of carrying capacity of relative economic resources, the central and southeast was higher than the western and northern regions, of which Shanghai had the highest economic carrying capacity of 35,159,000, followed by Beijing, Tianjin, Guangzhou and Shenzhen (Fig. 4).

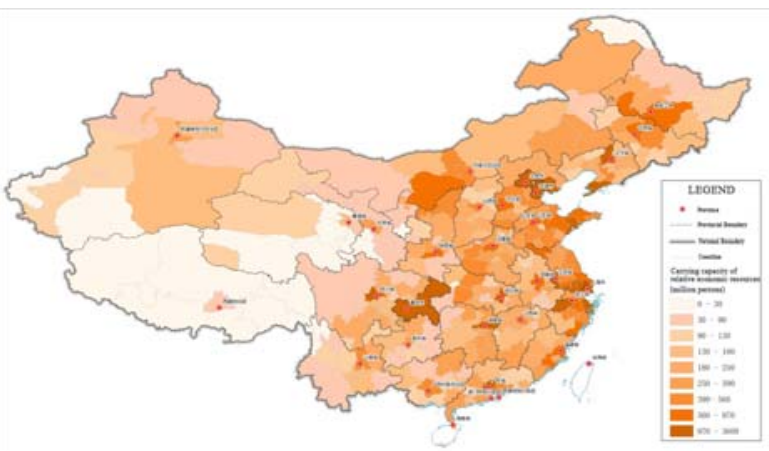

Figure 4. Carrying capacity of relative economic resources in China

\subsection{Comprehensive CCRR}

According to the statistical calculation data of relative resource carrying capacity in 2012 , about $43 \%$ of the prefectural cities' CCRR was overloaded. The top ten cities where the status of carrying capacity of resources was overloaded were Wenzhou, Shanghai, Chengdu, Baoding, Shantou, Jieyang, Dongguan, Fuyang, Zhoukou and Handan. The cities were basically distributed in the central and southern areas with convenient transportation and more economically developed areas. Among the cities in surplus status, resources carrying capacity in Hulun Buir was the most abundant, followed by Heihe, Bayingolin Mongol Autonomous Prefecture, Qiqihar, Chifeng and Jiamusi, all of which were located in northeastern China with a small population and plentiful cultivated land (Fig. 5).

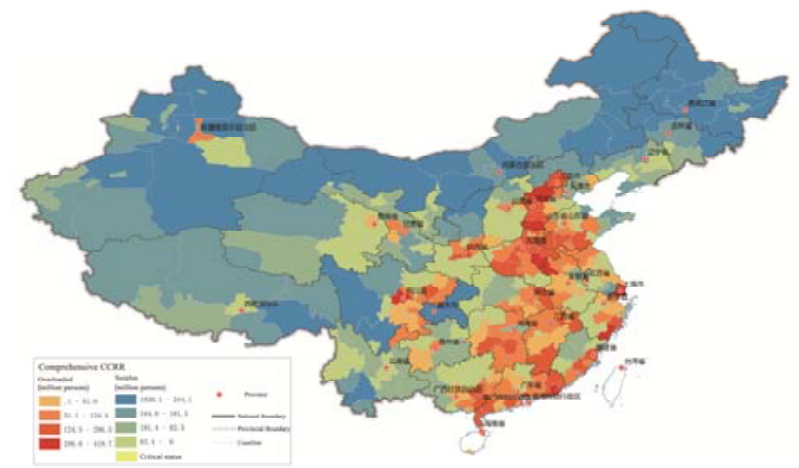

Figure 5. Comprehensive CCRR in China

\section{CONCLUSION}

According to the comparison of CCRR results and the actual permanent resident population among 342 cities surveyed, the status of resources carrying capacity in 147 cities was overloaded, while that in the remaining 194 cities was surplus. The top ten cities where the status of carrying capacity of resources was overloaded were Wenzhou, Shanghai, Chengdu, Baoding, Shantou, Jieyang, Dongguan, Fuyang, Zhoukou and Handan. The cities were basically distributed in the central and southern areas with convenient transportation and more economically developed areas. Among the cities in surplus status, resources carrying capacity in Hulun Buir was the most abundant, followed by Heihe, Bayingolin Mongol Autonomous Prefecture, Qiqihar, Chifeng and Jiamusi, all of which were located in northeastern China with a small population and plentiful cultivated land.

The research had two innovative points. Innovative point 1: Put forward an improved CCRR assessment model, in which arable land resource productivity could be accurately evaluated using remote sensing and GIS technologies. Innovation 2: It was the first time to obtain a spatial and quantitative analysis and evaluation result of the comprehensive resource carrying capacity at country scale based on 1: 250000 basic geographic information data.

\section{ACKNOWLEDGEMENTS}

Thanks to the support of National Key Research and Development Program of China (NO. 2016YFB0501403).

\section{REFERENCES}

Allan W A, 1949. Studies in African Land Usage in Northern Rhodesia Rhodes Livingatone Paper and NO. 15. Cape Town: Oxford University Press.

Di Q B, Han Z L, Liu G C, 2007. Carrying capacity of marine region in Liaoning Province. Chinese Geographical Science, 17(3), pp. 229-235.

Huang N S, Kuang Y Q, 2000. The carrying capacity of resources and the problems of sustainable development in Guangdong Province. Economic Geography, 20(2), pp. 52-56. Niu W Y, 1994. Introduction to Sustainable Development. Beijing: Science Press. 
Tao Z P, 2003. Eco-sack and Eco-footprint. Beijing: Science Press.

Wackernagel M, Onislo L, Bello P, et al., 1997. Ecological Footprints of Nations. Toronto: International Council for Local Environmental Initiatives.

Wackernagel M, Rees W E, 1996. Our Ecological Footprint: Reducing Human Impact on the Earth. Gabriola Island: New Society Publishers.

Zhang Z D, 2004. Carrying capacity of resources and problems of sustainable development in Pearl River Drainage area. Economic Geography, 24(6), pp. 758-763. 